\title{
AC 2008-1006: HIGH SCHOOL OUTREACH PROGRAM: ATTRACTING YOUNG LADIES WITH "ENGINEERING IN HEALTH CARE"
}

\section{Tania Monterastelli, University of Maryland-Baltimore County}

Tania Monterastelli graduated Summa Cum Laude in 2008 with a BS degree in Chemical Engineering from the University of Maryland, Baltimore County. She is a member of Phi Kappa Phi and Tau Beta Pi. She has been working on the YESS program for the last two years. In July 2008 she will begin her career with Exxon-Mobile Corporation.

\section{Taryn Bayles, University of Maryland-Baltimore County}

Taryn Bayles is a Professor of the Practice of Chemical Engineering in the Chemical and Biochemical Engineering Department at UMBC, where she incorporates her industrial experience by bringing practical examples and interactive learning to help students understand fundamental engineering principles. Her current research focuses on engineering education, outreach and curriculum development.

\section{Julia Ross, University of Maryland-Baltimore County}

Julia Ross is Professor and Chair of the Chemical and Biochemical Engineering Department at the University of Maryland, Baltimore County. Her technical research interests are in the area of cellular engineering. In particular, her work focuses on bacterial adhesion to physiological surfaces. In addition, she maintains an active research program in curriculum development with a focus on workforce development. She is also the 2007 recipient of the ASEE Sharon Keillor Award for Women in Engineering Education. 


\title{
High School Outreach Program: Attracting Young Ladies with "Engineering in Health Care"
}

\begin{abstract}
$\underline{\text { Abstract }}$
YESS (Young Engineers and Scientists Seminars) is an enrichment program for gifted and talented high school students from the Baltimore/Washington areas who have a strong aptitude in mathematics and science fields. The program, founded in 2002, is funded by the Historical Electronics Museum with a grant from Northrop Grumman. Previous YESS speakers have addressed diverse topics such as plasma physics, stealth radar, biomedical imagery, super computers/micro technology, aeronautical engineering, astrophysics and satellite reconnaissance.

In recent years, the program has been revised from a strictly seminar series to a hands-on program designed to help students understand the engineering design process. Since revising the format of the program, average attendance has more than tripled to a 2006-7 level of 107 students. Two-hour sessions are held biweekly and students learn how to go from brainstorming to designing, building, and testing. In an attempt to attract more young ladies to the program (as well as to encourage them to pursue engineering as a career), the 2007-8 program focuses on "Engineering in Health Care". The percent of females attending the program in recent years has ranged from $10-28 \%$.

Each week, a presentation is made on a topic related to engineering in health care. New this year, the featured speakers are young ladies who are studying engineering (as undergraduate or graduate students) or are medical students who have undergraduate engineering degrees. One of the presenters has also worked in the National Institute of Biomedical Imaging and Bioengineering at the National Institutes of Health. At the conclusion of each presentation, students participate in mini hands-on design challenges, which require the utilization of newlylearned concepts as well as general engineering methods. Following the sessions of seminars and mini challenges, the students must combine concepts they have learned to design, construct and test an efficient and cost effective hemodialysis system which removes 'impurities' from simulated blood.

The overall effectiveness of the YESS program is determined based on observation of an improvement in implementation of engineering concepts and methods as the program progresses. To assist with this analysis, each team is required to keep a design notebook to document the evolution of the final design. In addition, participants complete pre- and post-surveys measuring interest, attitude and content knowledge of the engineering design process and the underlying principles associated with a successful hemodialysis design solution. The results of these findings are documented, compiled, and presented. Since this is the fourth year of this revised program, comparisons are made to examine the evolution and the success of this high school outreach program; as well as to determine if the "Engineering in Health Care" topic is successful in attracting more young ladies to this high school enrichment program.
\end{abstract}




\section{Background}

The Young Engineers and Scientist Seminars (YESS) program was developed by the Historical Electronics Museum, and debuted in the fall of 2002. The mission of the Historical Electronics Museum is to educate industry, government, students, and the general public on the evolution and the importance of defense and commercial electronics of the past through the exhibition and interpretation of historically significant artifacts and documents related to electronics technology ${ }^{1}$. The education goal of the museum is to provide visitors with an understanding of the basic concept of electronics and an appreciation of evolutionary milestones of sophisticated electronics systems. In support of these objectives, the museum's priority is to provide a motivational environment for students of all ages to gain an understanding of basic engineering and the career opportunities available through higher education. It was with this priority in mind that the Historical Electronics Museum began the YESS program. The program was intended for highly gifted high school students in the Baltimore/Washington area with a strong aptitude in mathematics and/or science.

The first two years of the program consisted solely of a series of lecture based seminars covering topics as diverse and dynamic as plasma physics, stealth astrophysics, and satellite reconnaissance. The 2003 seminar program sparked a soon to be dynamic change in the format and structure of the program. Two University of Maryland, Baltimore County professors who presented a lecture entitled "Careers in Engineering and Introduction to Engineering Design" were the impetus for change. Their innovative, engaging, and "hands-on" style lecture impressed the Board of Directors at the museum and was rated with great enthusiasm by the students who participated in the lecture. This sparked the Board of Directors at the museum, in the summer of 2004, to consult with one of the University of Maryland, Baltimore County professors (and co-author of this paper) who presented in the 2003 program regarding the possibility of revising the program to incorporate active learning and project-based lectures.

The general format of the restructured YESS program now includes weekly guest speakers followed by an episode of Who Wants to Be an Engineer (a game developed by Professor David Silverstein ${ }^{2}$ from the University of Kentucky, Paducah) and a weekly hands-on activity. This year the program was designed to instruct the high school students on how to move from brainstorming a problem to designing, building, and finally testing a solution.

As a result of the restructured program, attendance has steadily grown through the years. Comments attained from both students and parents have reflected that the introduction of the weekly hands-on activities to supplement the guest lecturers has provided an enjoyable addition to each seminar. ${ }^{3}$

In order to gather enrollment, letters were sent to Science, Technology, Engineering and Mathematics (STEM) high school coordinators from Anne Arundel, Howard, Harford, Queen Anne's, Baltimore, and Carroll counties, as well as the City of Baltimore, inviting them to nominate students (teachers and parents are also welcome) for the program. To help keep all participants connected to the program, a website ${ }^{4}$ was created to provide updated information, including specifications for the overall design project, archived presentations from prior seminar 
dates, and photos and videos of the weekly hands-on activities. IRB approval was secured for the project and students were asked to submit release forms with his/her signature along with that of a parent or guardian prior to any participation.

The effectiveness of the YESS program is assessed through the distribution of surveys that capture self-reported data from the students regarding demographic information, parent/guardian occupations, interest levels in relevant fields, level of understanding in key content area, measures of confidence in math and science, and expectations for the program.

The 2007-8 program marked a special interest in obtaining greater female participation in the series. Reports have shown that "technological illiteracy among the general population may be linked to the lack of diversity in the engineering profession,", and more specifically a "lack of visible role models and other women students in engineering." Therefore, the recruitment of more students into STEM-related careers, particularly women and minorities, begins by stimulating interest and providing a strong foundational skill set to students. ${ }^{6}$ It is with this perspective that the YESS program is trying to increase its enrollment of young women. In an effort to accomplish this goal, this year's program focused on engineering in healthcare. The overarching design project revolved around designing, building, and testing a hemodialysis system. Weekly guest speakers, the majority of whom were women, were chosen to demonstrate through personal experience how engineering is applicable to healthcare and the opportunities available in bioengineering. The hands-on activities were all geared towards preparing the students for the final design project.

This year's program met every other Thursday, at 7:00 PM, from October 11 through December 13, with final project testing took place on January 10. Enrollment in the program was free of charge for students and a complementary dinner buffet was provided by the Hilton Baltimore BWI Airport hotel prior to the start of each session. During the program a guided tour of the Northrop Grumman site located near BWI (November 1) was arranged for the students. In an effort to reward student participation, dedication, and interest in the program, numerous opportunities to win gift card prizes for Best Buy ${ }^{\mathrm{TM}}$ were provided. Cash prizes were also awarded to the top performing design projects at the final evening of the YESS program.

\section{Weekly Seminars}

The 7 week YESS seminar program was designed to inform students about the field of engineering, including its importance and opportunities, as well as to expose students to thinking like an engineer. These goals were accomplished through presentations from weekly guest speakers and games and design challenges held throughout the seminar.

This year, the majority of guest speakers were young ladies studying engineering (either at the undergraduate or graduate level) or medical students who previously completed an undergraduate degree in engineering. The decision to invite mainly female speakers was made in order to show students that women are equally as important to the field of engineering as men. Additionally, the women were chosen because their studies were related to bio-engineering which was the theme of this year's program. The women were able to provide unique 
perspectives on what it takes to be an engineer, especially a female engineer, and the opportunities available. The educational diversity of the speakers was also chosen in order to create a link between the students and speakers, since many of the students are close to beginning their collegiate careers.

Following each presentation, students participated in the popular Who Wants to Be an Engineer game. The game is interactive and required students to match answers to engineering questions by raising color coordinated index cards as the questions were displayed by the projector. Correct answers were rewarded by giving students a "YESS buck" as shown in Figure 1, redeemable for gift cards upon conclusion of the program.

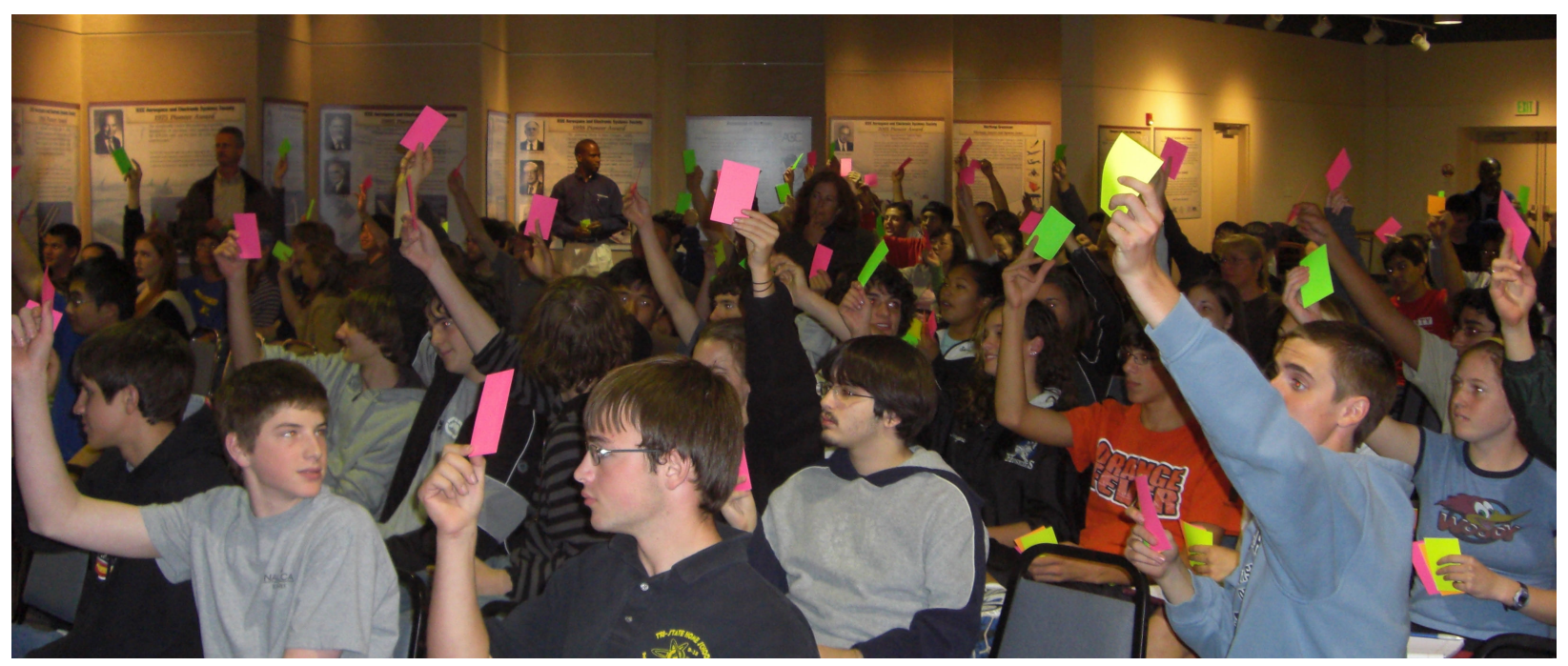

Figure 1: Who Wants To Be An Engineer Activity

Each weekly session concluded with a different hands-on design challenge designed to prepare the students for the program's overarching design project—building a hemodialysis system. The hemodialysis design project involved separating impurities from simulated blood, with this in mind the hands-on challenges were designed to get students thinking about separation techniques as well as the basic principles of fluid flow.

\section{Week 1: Introduction to Engineering}

The opening presentation of the 2007-8 YESS program on October 11 featured one of the coauthors presenting an overview on the field of engineering. To engage the student audience, the presentation began with a list of the greatest engineering achievements of the $20^{\text {th }}$ century with an emphasis on the extreme importance of this field to societal and technological development. The presentation continued with a description of engineering by outlining the various types of engineers, including specific opportunities, possible jobs, salary outlook, and requirements for becoming an engineer. The presentation concluded with an overview of the Introduction to Engineering Design course at the University of Maryland, Baltimore County. The overview 
featured several videos of previously used design projects to allow students to realize what will be expected upon entering the field of engineering.

\section{Hands-On Activity \#1: \\ Reach for the Stars!!!!}

The goal of this activity was to introduce students to working in groups while executing a task relative to engineering. The students were instructed to design and construct a freestanding structure to the maximum height possible while minimizing total cost. At the beginning of the activity each team was given a bag of assorted Tinker Toys which they were not allowed to open. The teams were then given 20 minutes to design and plan their structures (without using the materials), and only 3 minutes for construction.

\section{Week 2: The Engineering Method}

On October 18, a Chief Scientist of Space Systems at Northrop Grumman delivered a presentation on the engineering method. The speaker emphasized the importance of planning throughout the entire engineering process and included several examples of engineering accomplishments, explaining how the engineering method applied to the development of each. Even more interesting was the presentation of several disasters of engineering such as the Leaning Tower of Pisa and the identification of possible errors in the engineering method that may have led to the various failures.

\section{Hands-On Activity \#2:}

\section{Eek! Don't Let it Leak!!!!}

The goal of this activity was to introduce students to engineering design and planning by asking them to construct a device to protect an egg from a 10 foot drop while minimizing mass and cost. Students were given 20 minutes to design and construct their devices. Criteria for a successful drop included being able to easily remove the egg after the drop and having a completely intact egg. The mass of the device (without the egg) was then measured at the end of the drop. Materials provided included such items as plastic bags, cotton balls, pipe cleaners, tape, cups, rubber bands, and straws.

One of the teams with their winning design is shown in Figure 2. 


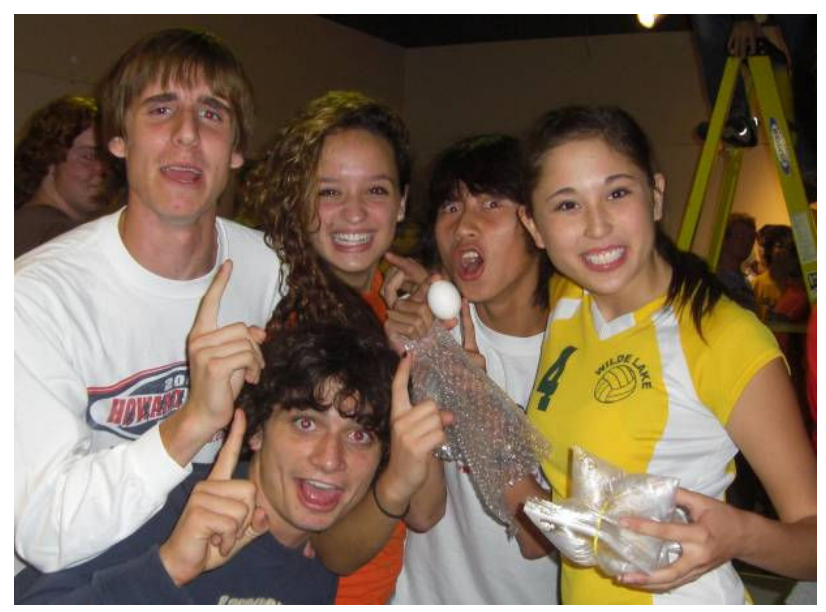

Figure 2: One of the Eek! Don't Let it Leak Challenge Winning Teams.

\section{Week 3: Why Be an Engineer?}

On November 1, a female Ph.D candidate in Chemical and Biochemical Engineering at the University of Maryland, Baltimore County delivered a presentation on why to be an engineer. The candidate discussed reasons and advantages to becoming an engineer. She also shared with the students her own personal experiences in studying engineering and entering the Ph.D program. Being an international student, it was of great interest to hear her account of obtaining her Bachelor's degree in Portugal prior to moving to the United States to continue her engineering studies. The speaker provided brief descriptions of the research she has been conducting in the area of Alzheimer's disease. She concluded by sharing her experience working with a major pharmaceutical company, Wyeth.

\section{Hands-On Activity \#3:}

Separate This!!!

In this challenge, students were given twenty minutes to design and construct a device, or series of devices, to separate sand from a mixture of components (salt, rice, cornstarch, glitter, metal filings, and B-B's). Teams were required to use no more than four process steps/devices for their separation, and were not allowed to touch the mixture of components or use any of the materials as chop-sticks to remove components. The materials provided included items such as screens, coffee filters, magnets, cups and plates. The goal of this activity was to for students to begin thinking about separation processes, an integral part of their overall design project.

Figure 3 shows images of one of the teams separating their mixture. 


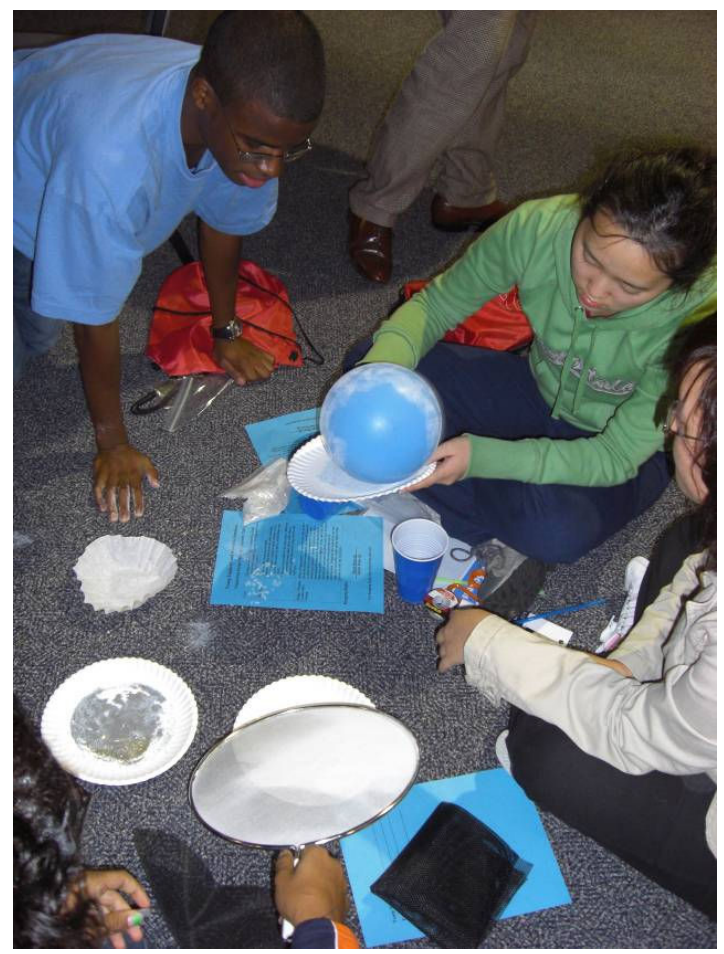

Figure 3: Separate This Challenge

\section{Week 4: Engineering and Medicine}

On November 15, a female doctor from the University of Maryland School of Medicine, discussed her career path from graduating with a degree in Mechanical Engineering to becoming a doctor. This presentation allowed students to see how diverse a degree in engineering can be, that engineering allows students to pursue careers that aren't specifically related to engineering. She also described much of the research she has conducted both in school and professionally. This presentation allowed students to see the importance that a strong, technical background, such as engineering, can have in society.

\section{Hands-On Activity \#4:}

Snap, Krackle \& Pop!

During this activity, students were able to gain experience with separating another mixture of components. This project featured similar methods to that of Separate This! The objective of this challenge was to separate Rice Krispies ${ }^{\circledR}$ from a mixture of 6 other cereals, while minimizing the cost of resources used. Again, this activity was designed to have students think about separation processes, but this activity differed from Separate This! in that it also required students to consider the impact of cost on separation processes.

Figure 4 shows a team separating their mixture. 


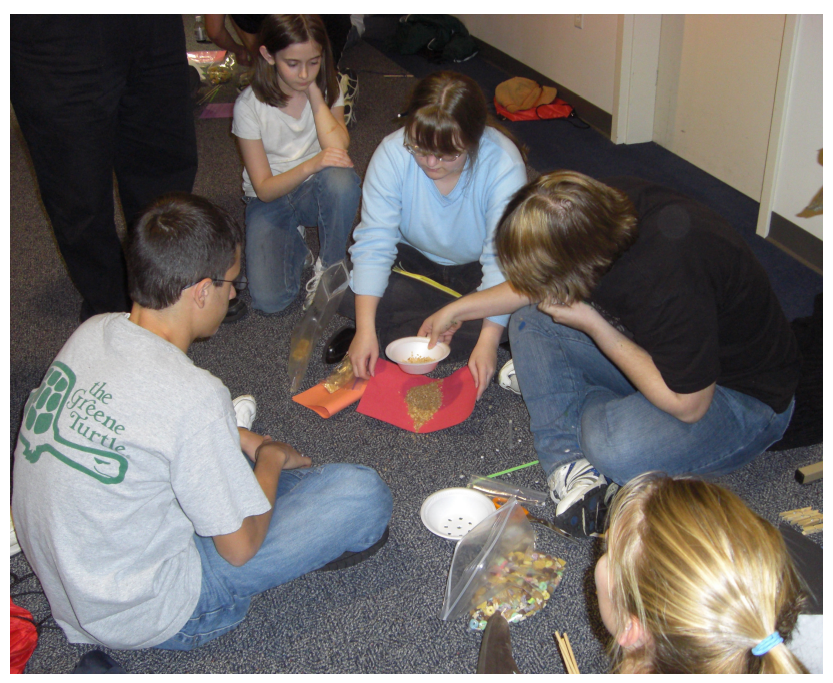

Figure 4: Snap, Krackle \& Pop Challenge

\section{Week 5: Engineering Your Future!}

On November 27, a group of 5 female engineers from the Clark School of Engineering at the University of Maryland, College Park presented on their experiences as undergraduate engineers. Each of the speakers had a different background in engineering which provided the students with exposure to a wide breadth of engineering areas. The speakers also provided the students with advice on what it takes to make it into engineering programs at a university. This perspective will be beneficial to the students while they consider what universities to apply to and what that means to their high school careers.

\section{Hands-On Activity \#5: \\ Let it Flow!}

The objective of this activity was for each team to build an apparatus to transfer $500 \mathrm{ml}$ of water a distance of 4 feet as quickly as possible, while minimizing cost. Teams were required to use at least one vinyl tube, though multiple tubes of different diameters could be used. During testing the time to transport all of the water a distance of 4 feet was recorded. Additionally, the final water volume was measured. It was important for teams to take care in minimizing water spills during testing. This activity was designed to instruct students on the basic principles of fluid flow.

\section{The Design Project}

The overarching design project in this year's program was to design, construct, test, and evaluate a device which simulates a hemodialysis system. The overall goal of the project was to maximize the removal of the impurities from simulated blood while using a minimum amount of dialysate (water) and minimizing the total cost of the system. 
Students were given $500 \mathrm{ml}$ of simulated blood to test their hemodialysis systems. Additionally, 4 different dialysis membranes were available for "purchase" from the program coordinator. All supplies were provided by the Chemical and Biochemical Engineering Department at the University of Maryland, Baltimore County under the NSF funded $\underline{\mathbf{S}}$ cience, Technology, Engineering and Mathematics Talent Expansion Program (STEP-DUE-0230148) and the

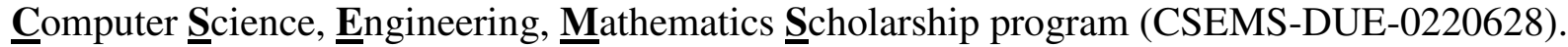
These grants also funded all materials purchased for the weekly hands-on activities.

The primary criterion for the design project was SAFETY; the system must operate without any hazards. There was a cost restriction of $\$ 75.00$ placed on the overall design, which must include ALL parts utilized in the design. While students were encouraged to scavenge and use materials from sources outside the program, they were required to price those as if they were newly purchased. Lastly, students were required to maintain a design notebook (also provided by program coordinators) which summarizes the evolution of their design.

Product performance was assessed using the following performance metric, which is a function of the amount of impurities removed, dialysate cost index and device cost index:

\section{Removal of impurities (in mg) x Dialysate Cost Index x Device Cost Index}

To determine the final removal of impurities from the simulated blood, the student teams multiply the quantity of dialysate used during testing by the standards concentration which is the best visual match of their final dialysate and the standard. The minimum removal of impurities from the simulated blood was $2.5 \mathrm{mg}$.

The dialysate cost index refers to the minimum dialysate cost for a design of a team participating in the YESS program divided by the cost of the team being tested. The minimum dialysate cost was determined from the team who used the least amount of dialysate while still removing at least $2.5 \mathrm{mg}$ of impurities.

The device cost index simply refers to the minimum design cost of a hemodialysis system divided by the cost of the team being tested. Again, the team with the least expensive design still had to meet the minimum impurity removal requirement.

All of the "bragging rights" calculations were executed by YESS program coordinators after the conclusion of testing.

This design project was developed based on the Health Care Module for the NSF funded (ESIE -

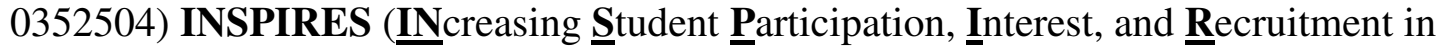
$\underline{\text { Engineering and }} \underline{\mathbf{S}}$ cience) curriculum, also developed in the Chemical and Biochemical Engineering Department at the University of Maryland, Baltimore County. 


\section{$\underline{\text { Results and Conclusions }}$}

Since the inception of the Young Engineers and Scientists Seminar program in 2002 the Board of Directors of the Historical Electronics Museum have taken great strides to create an interactive, engaging and informative program to stimulate an interest in engineering in high school students from the Baltimore/Washington area. Every year the Board of Directors and the program coordinator from the University of Maryland, Baltimore County have dedicated much time in attracting greater attendance to the program. In the 2007-8 program year, special emphasis has been placed on attracting more female students to engineering.

Since the YESS program was restructured in 2004, attendance has nearly tripled. Every year the general format of the program remains the same while the design project, mini design challenges and seminar lecturers change. Design projects have ranged from hot air balloons to mouse trap cars to energy systems and to this year's hemodialysis systems. Every year the top third or fourth place teams have been awarded monetary prizes, provided by Northrop Grumman, for the success of their designs.

This year's program saw 61-98 students throughout the series, averaging 86 students per session with 25 students having attended all of the sessions. $67 \%$ of students were male and $33 \%$ female, which corresponds to an increase in female attendance of 5\% from the 2006-7 program. Additionally, $80 \%$ of student participants were at junior and senior high school grade levels.

Overall attendance since 2002 has more than tripled, with female participation increasing by nearly 30\% since 2004; and the Board of Directors of the museum have expressed their delight with this improved attendance over the last several years. Comments from many of the students and parents during the YESS programs have indicated that the hands-on activities and the design project have been enjoyable and valuable additions to the seminars. One parent had this to say:

"My children really enjoyed the program. They were able to see, hear, and learn about engineering hands-on so they can make the best informed decision if they are considering engineering as a career. Dr. Bayles brought in some really good role models for the kids to see and hear about. I feel that has had a very beneficial effect, especially on my daughter who doesn't get to see a lot of female role models in technology areas."

To assess the effectiveness of this year's YESS program, student participants completed surveys at the beginning and end of the seminar series. The surveys were designed to capture changes in student interest in science and engineering as well as a host of related attitudes and confidence levels related to math, science, and engineering of interest to the seminar designers. 66 presurveys and 78 post-surveys were collected in this year's program, and 18 students submitted both a pre- and post-survey.

It was the intent of this year's YESS series topic, "Engineering in Healthcare", to be an attraction for young women. Statistics have shown that women out number men in professional occupations such as medical and health services, physical therapy, and nursing. ${ }^{7}$ Based on these statistics, the program's goal was to attract young women with the idea of healthcare, while exposing them to the opportunities of engineering. In order to assess whether the topic of 
healthcare was in fact a deciding factor for female participation, students were asked to rate their agreement with the statements listed in Table 1. Students evaluated these statements according to a 1-to-5 rating system where 1 indicated "strongly disagree" and 5 indicated "strongly agree." The average responses are also shown in the table.

Table 1. Student Responses for their Interest in the 2007-8 YESS Program Topic of "Engineering in Healthcare"

\begin{tabular}{|l|c|c|c|}
\hline Question & Overall & Male & Female \\
\hline $\begin{array}{l}\text { I participated in the YESS program because } \\
\text { of the focus on healthcare. }\end{array}$ & 2.2 & 2.2 & 2.2 \\
\hline $\begin{array}{l}\text { This program has made me more interested } \\
\text { in engineering and healthcare }\end{array}$ & 3.0 & 3.0 & 3.1 \\
\hline $\begin{array}{l}\text { I would be interested in future programs } \\
\text { focused on engineering and healthcare }\end{array}$ & 3.2 & 3.1 & 3.4 \\
\hline
\end{tabular}

Interestingly, the data would indicate that the focus on healthcare was not a major attraction to the program for either male or female participants. However, by the end of the seminar ${ }^{8}$ even though students may not have initially participated specifically because of the topic, their interest levels for the topic did increase. The data shows female interest levels for healthcare were slightly higher than those of the male students; however, a t-test performed on the two data sets indicates no statistical significance between these differences $(\mathrm{p}>0.05)$.

Overall, survey results showed that female interest in the YESS series increased by $15 \%$ from the beginning to the end of this year's program. Comparatively, last year's seminar showed a decrease in female interest by $11 \%$. Last year's focus was on renewable energy with a final design project requiring teams to design systems to collect, store, transport, convert, and utilize energy from renewable sources such as water, sunlight, or wind. Similarly, the 2005-6 series ${ }^{9}$ which featured designing mouse trap cars saw only a $2 \%$ increase in female interest for the program. These statistics would indicate that the topic of healthcare was of greatest interest for female students throughout the YESS program.

Another series of statements was designed to capture changes in student interest in science and engineering, as well as changes in attitudes and confidence levels with respect to science, engineering, math, and team problem solving. The responses to these statements were analyzed based on all participants, as well as by looking specifically at female and male student responses. The results are shown in Figure 5, where the numbers 1 through 6 correspond to the following statements:

1. My interesting in pursuing a career in science or engineering has

2. My interest in teamwork has

3. My ability to work on teams has

4. My confidence in successfully studying science or engineering in college has

5. My understanding of how math helps solve problems in science and engineering has

6. My knowledge of science and engineering fields has 


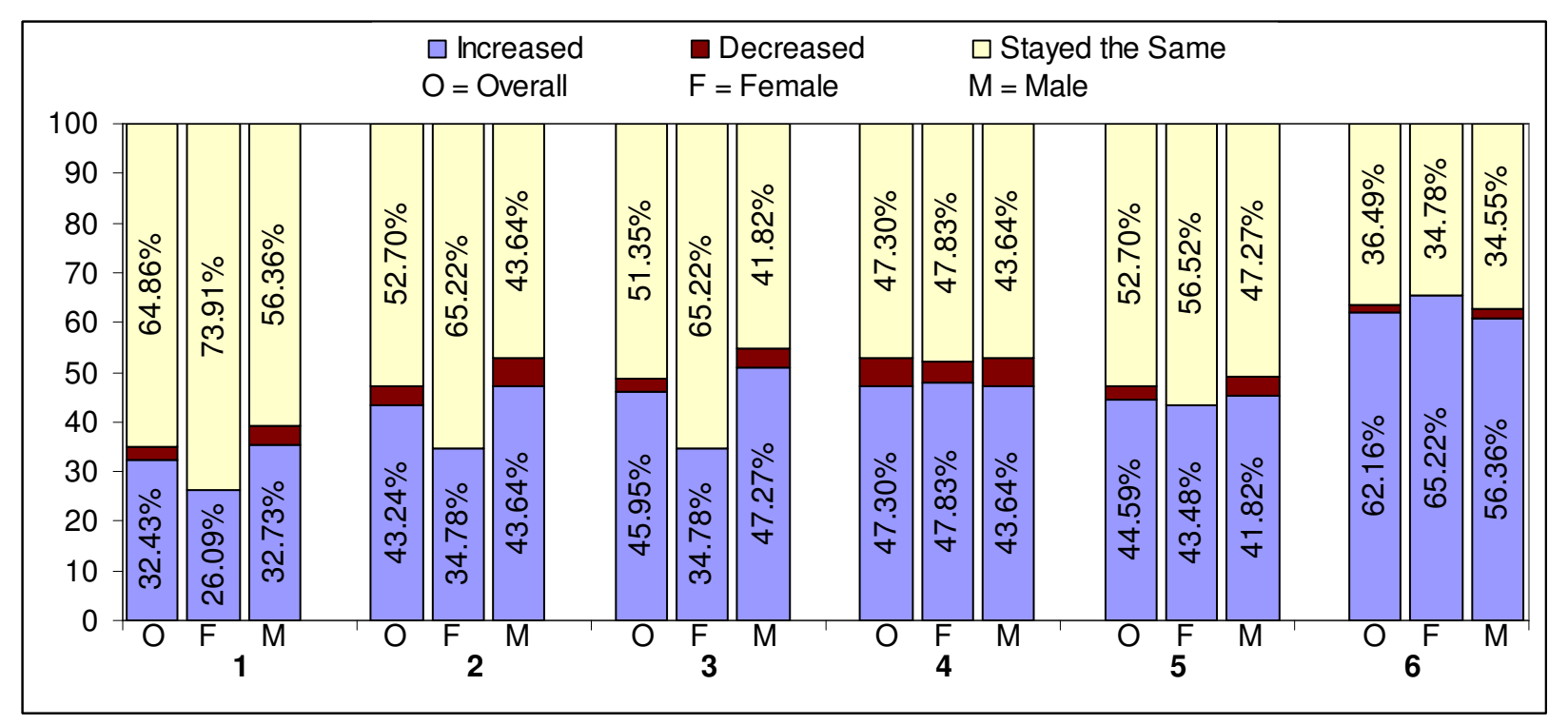

Figure 5. Student Reponses to Changes in their Interest, Attitude, and Confidence Levels

Numerous questions pertaining to students' understanding of key content areas were presented as identical questions on both the pre- and post- surveys. To answer these questions, students were asked to rate their understanding of content on a 1-to-5 scale (where 1 indicated "weak" and 5 indicated "strong") and to answer a series of multiple choice questions. Additionally, the students' understanding of the engineering design process was evaluated by having them order the nine design process steps. By pairing pre- and post-survey data a more detailed analysis of student performance could be performed. The data shown in Table 2 represents the percentage of students who indicated an improvement in their understanding of the listed topics.

Table 2. Percentage of Students who Indicated an Improvement in their Understanding of the Key Content Areas of the 2007-8 YESS Program

\begin{tabular}{|l|c|}
\hline Content Area & Percentage of Improved Students (\%) \\
\hline Dialysis & 83.33 \\
\hline Diffusion & 72.22 \\
\hline Concentration gradient & 77.78 \\
\hline $\begin{array}{l}\text { Relationship between diffusion, } \\
\text { concentration, and temperature }\end{array}$ & 61.11 \\
\hline Co-current / counter-current flow & 83.33 \\
\hline Engineering design process & 72.22 \\
\hline
\end{tabular}

The responses to the multiple choice questions for the pre- and post- surveys were analyzed using a paired sample t-test. The average score for the multiple choice section increased from $68 \%$ on the pre-survey to $88 \%$ on the post-survey. A paired t-test indicated that this increase was statistically significant $(\mathrm{p}<0.05)$. On the other hand, a paired t-test indicated that the decrease from $72 \%$ to $68 \%$ on the survey scores for ordering the design process steps was not statistically significant ( $\mathrm{p}>0.05)$. Although students were tested on their ability to learn and retain technical information throughout the course of the program, student performance in this area is not the 
main focus of the YESS program as it is difficult to expect students to retain technical information while participating in a volunteer program. It is for this reason that the real emphasis of the program is to attract students to science and engineering, and make them aware of the opportunities and fields of interest available to them.

Open-ended questions were also included on the post-surveys to complement the quantitative data. These questions afforded students the opportunity to freely comment about their favorite part of the program as well as their personal experience in the YESS program. 68 students provided feedback regarding their favorite part of the program, and $37 \%$ commented that the hands-on activities were the best part of the program. The following are several of the student's responses regarding their experiences in the YESS program:

- "It really made me enjoy engineering and I am now a lot more interested in the engineering field."

- "YESS, to me, provided an ample opportunity to study engineering options, a field I have been considering for the future."

- "I am interested in a job related to engineering/medicine so this program was a good opportunity to learn more about the fields."

Increased student participation in the 2007-8 YESS program, especially from females, is an indication of the program's continued success of attracting young students to science and engineering. Data gathered throughout the program demonstrates the success an interactive, hands-on style learning approach can have on improving student understanding of engineering concepts, as well as increasing student confidence levels. Based on the positive feedback and support from students and parents, it is the intent of the Board of Directors of the Historical Electronics Museum in conjunction with the Program Coordinator from the University of Maryland, Baltimore County to continue to expand the YESS program in the future.

In addition to the data presented in this paper, YESS student participants will be asked to complete a third survey at the end of the school year to determine whether or not the YESS program has influenced their choice of study in college.

\section{Acknowledgement}

The authors wish to acknowledge the financial support for this program from Northrop Grumman and the Historical Electronics Museum; the Hilton Baltimore BWI Airport hotel for providing food and program space every week; the National Science Foundation for our

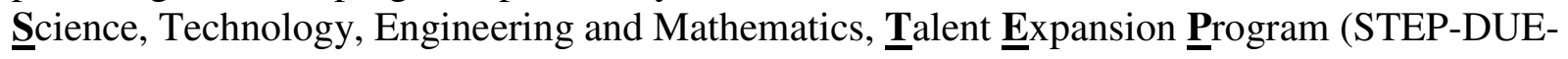

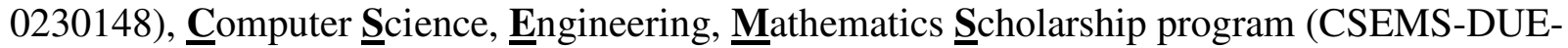
0220628), and funding of a mini-grant from the NSF funded Conducting Rigorous Research Education: Creating a Community of Practice (DUE-0341127). 


\section{Bibliographic Information}

1. Marks-Persinger, K.D., Editor, Reflections, The Historical Electronics Museum Newsletter, Volume 13, Issue 3, Fall/Winter 2003.

2. $\quad$ Silverstein, D.L. "Who Wants to be an Engineer?", Proceedings of the 2003 American Society for Engineering Education Annual conference \& Exposition, presented in the ASEE Multimedia Session \#2793 at the ASEE Annual Conference, Nashville, TN, June 24, 2003.

3. $\quad$ Bayles, T.M., A.M. Spence and J. Brown Leonard, "YESS - Young Engineers \& Scientists Seminars" Paper \#1378 published in the Proceedings of the 2005 American Society for Engineering Education Annual Conference \& Exposition. Presented in the K-12 Engineering \& Pre-College Outreach Session \#1510 at the ASEE Annual Conference, Portland, OR, June 13, 2005.

4. http://www.yesshem.com, accessed December 10, 2007.

5. S.E. Widnall. Digits of Pi: Barriers and Enables for Women in Engineering. The Bridge 30 (2000)

6. National Academies Press, 2006. Rising Above the Gathering Storm.

7. U.S. Department of Labor. February $22,2008<\mathrm{http}: / /$ www.dol.gov/wb/stats/main.htm>.

8. Rice, J., T. M. Bayles, G. Russ, and J. Ross, "Preparing Freshmen for Future Energy Issues", Paper AC 2007-1748 published in the Proceedings of the 2007 American Society for Engineering Education Annual Conference \& Exposition. Presented in the Hands-on \& Real world Studies Session in The Freshman Programs Division Session \#2253 at the ASEE Annual Conference, Honolulu, HI, June 26, 2007.

9. $\quad$ Bayles, T.M., T. Foster, D. Sheridan and C. Parker, "Let it Roll with YESS", Paper \#2006-1255 published in the Proceedings of the 2006 American Society for Engineering Education Annual Conference \& Exposition. Presented in the K-12 Engineering \& Pre-College Outreach Session \#3667 at the ASEE Annual Conference, Chicago, IL, June 21, 2006. 